Provided for non-commercial research and education use. Not for reproduction, distribution or commercial use.

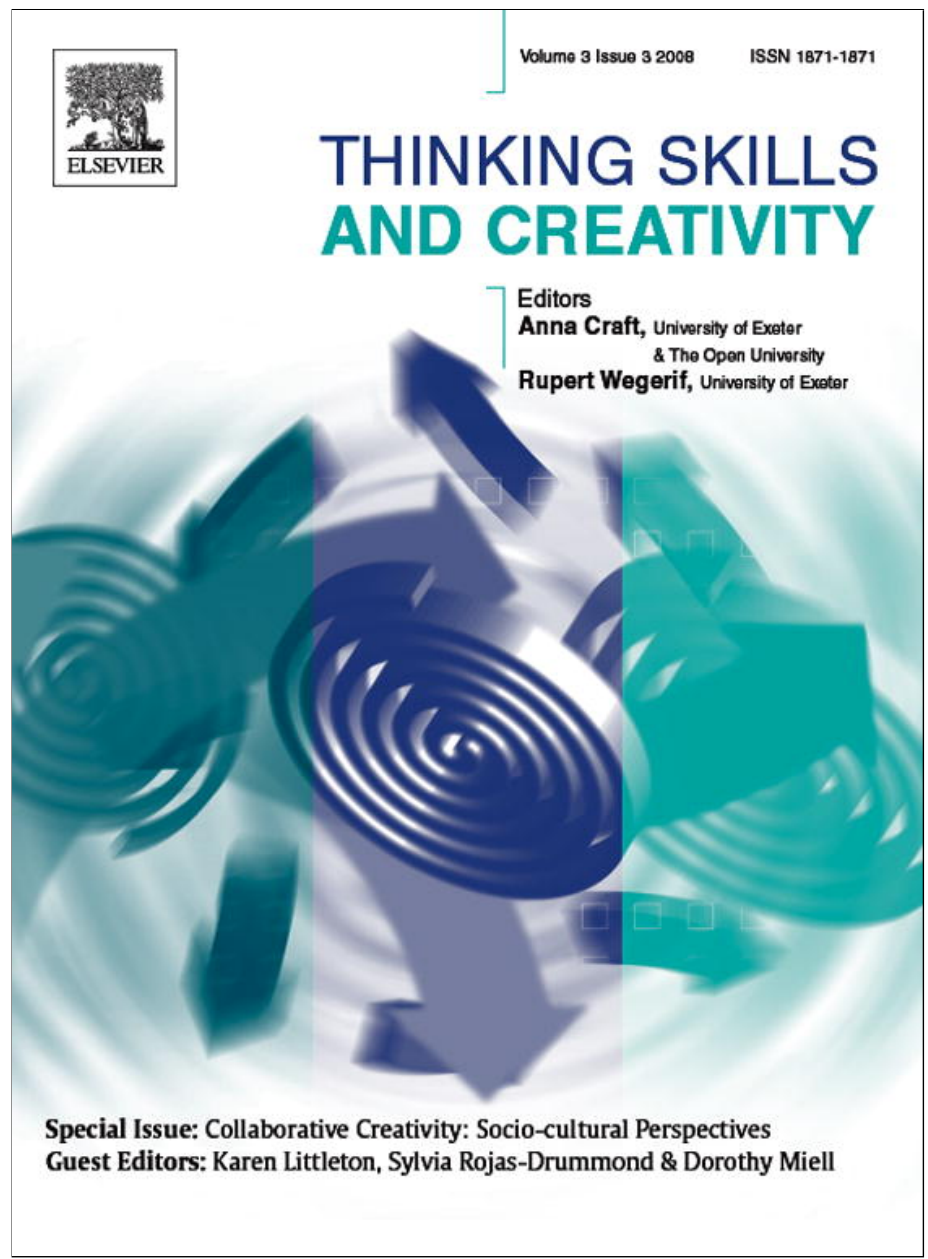

This article appeared in a journal published by Elsevier. The attached copy is furnished to the author for internal non-commercial research and education use, including for instruction at the authors institution and sharing with colleagues.

Other uses, including reproduction and distribution, or selling or licensing copies, or posting to personal, institutional or third party websites are prohibited.

In most cases authors are permitted to post their version of the article (e.g. in Word or Tex form) to their personal website or institutional repository. Authors requiring further information regarding Elsevier's archiving and manuscript policies are encouraged to visit:

http://www.elsevier.com/copyright 


\title{
The situated aspect of creativity in communicative events: How do children design web pages together?
}

\author{
Juan Manuel Fernández-Cárdenas* \\ Comité Regional Norte de Cooperación con la UNESCO Zaragoza 1300 Sur Edificio Kalos Nivel A2, Despacho 23564000 Monterrey, Nuevo León, Mexico
}

\section{A R T I C L E I N F O}

Article history:

Available online 30 September 2008

Keywords:

Collaboration

Literacy

Multimodality

Practice

Creativity

\section{A B S T R A C T}

This paper looks at the collaborative construction of web pages in History by a Year-4 group of children in a primary school in the UK. The aim of this paper is to find out:

(a) How did children interpret their involvement in this literacy practice?

(b) How the construction of web pages was interactionally accomplished? and

(c) How can creativity be identified in interaction?

Using an ethnographic approach to the study of communication, it is argued that the collective and creative construction of meaning can be understood in terms of relationships amongst components of communicative acts. The analysis of these components reveals how participants shape their utterances as they are engaged in the pursuit of shared goals in a situated activity system. It is argued that participants strive to become members of a community of practice designing web pages. Members of this community showed their understanding in relation to the way they interpreted the design rules for a multimodal text, the means for working together in collaboration and distributing roles, as well as their interpretation of what counts as historical knowledge. Also, in terms of creativity, participants managed to communicate and negotiate their intentions by using several figures of speech and language games, as well as contextually framing their positions as participants in a dialogue. That is, children and teacher demonstrated their creative abilities in a textual, contextual and critical level. It is concluded that creativity is not a gifted capacity; it is an everyday act which is interactionally accomplished in the context of social participation as members of a community. Members creatively display their intentions and negotiate new alternatives for the interpretation of actions in situated activity systems.

(c) 2008 Elsevier Ltd. All rights reserved.

\section{Literacy and ICT}

With the introduction of Information and Communication Technologies (ICT), literacy has been transformed in relation to the documents and the practices afforded by these new technologies. Therefore, the traditional conception of literacy in relation to the ability to read and write (Hornby, 2000; Pearsall, 1998) has been challenged by the emergence of 'new types of texts' associated with the possibility to construct, transform, and display them electronically. These new types of electronic texts include features such as a wider presence of audio-visual elements, the use of a more non-linear arrangement

\footnotetext{
* Tel.: +52 818344 2960; fax: +528183442962.

E-mail address: J.M.Fernandez@comitenorte.org.mx.

URL: http://www.comitenorte.org.mx/.
} 
of information, and an ever-changing nature linked to the processing speed and simulation capacity of computers and ICT networks (Mayer, 2000; Rassool, 1999). Examples of these texts include: e-mails, electronic concept maps, spreadsheets, power point presentations, and web pages, just to mention some examples.

In this respect, some authors have also argued that literacy should include the ability to read and write images (Flood, Heath, \& Lapp, 1997), given the increasing proliferation of 'multimodal' electronic texts as part of literacy practices at home, community settings, and particularly in classrooms (Jewitt \& Kress, 2003; Unsworth, 2001). A multimodal text then not only includes words, but also other semiotic modes of communication present in electronic (and other material) media, such as pictures, colours, backgrounds, icons, and sounds, amongst the possible audio-visual resources constituting texts. Thus, given the prominence and the variety of visual resources used in printed and electronic documents, for Kress and van Leeuwen (1996) literacy is conceived as being associated with the development of skills dealing with visual grammar in multimodal texts.

Similarly, authors like Reinking (1994) have suggested that the traditional conception of literacy should be expanded to include 'electronic reading and writing'. For Reinking, reading and writing in an electronic way aggregate new dimensions to literate activity beyond printed materials. Activities like keyboarding, word-processing, looking for information in databases, or reading a hypermedia document, require a new set of skills different to the ones used by students taught with the framework of the traditional concept of literacy in similar activities like handwriting, looking for information in catalogues or reading linear texts.

In addition, others have argued that with the use of ICT in everyday classroom activities, the practice of literacy has also started to have a greater convergence with the learning of subject areas of the curriculum (Leu \& Kinzer, 2000). That is, as information resources are networked and as literacy becomes more tightly defined around ICT in schools, it becomes more difficult to separate subject-area learning into distinctive categories and time periods during the day, and therefore it also becomes more difficult to separate literacy learning from the learning of Science, History, Geography, etc. According to Leu and Kinzer, increasingly, literacy learning takes place within information contexts whose boundaries disappear in a connected world of ICT resources.

In a related manner, researchers such as Labbo (1996), Labbo and Kuhn (1998) and Heath (2000) have asserted that reading and writing are becoming even more important in the integrative process of literacy with ICT. For instance, students increasingly need to effectively locate and read information to solve problems in several domains of the curriculum and then to communicate results to others electronically, and consequently, in written form. However, the same researchers have asserted that increasingly, children also need to be supported in learning how to learn about literacy from one another. That is, pupils need to learn to talk to each other in order to co-ordinate efforts to construct electronic texts. Therefore, issues of how to promote 'effective' collaboration in relation to the use of language and other semiotic resources in small groups are also a key concern of the research agenda in literacy as well as in other areas of education (e.g. Cowie \& van der Aalsvort, 2000; Dillenbourg, 1998).

\section{Creativity and literacy}

The literacy research agenda has not only been transformed by the wider use of ICT on everyday school activities. There are also concerns about how to promote creativity in the context of literacy practices. Creativity has been interpreted as a requirement for having the possibility to take multiple perspectives while working on a given area of the curriculum, particularly in arts and humanities (Craft, Dugal, Dyer, Jeffrey, \& Lyons, 1997; Craft, Jeffrey, \& Leibling, 2001). Thus, literacy education has been addressed by studying how children engage in creative writing using ICT tools (i.e. Vass, 2004 and Vass, Littleton, Miell, \& Jones, this issue). Moreover, creativity has been an issue when researchers have looked at the use of language in interaction (Wegerif, 2005) and for literacy purposes (Rojas-Drummond, Mazón, Fernández, \& Wegerif, 2006).

Vygotsky (2004) defines creativity as a "human act that gives rise to something new ... regardless of whether what is created is a physical object or some mental or emotional construct that lives within the person who created it and is only known to him' (p. 7). This definition highlights the qualities of novelty and originality that must bear a given object or human process to be consider creative. As such, creativity is a constant characteristic of human intentional activities as compared to others more mechanical actions in which a person might be involved. That is, a human act intended to communicate through meditational means, such as language and other material media, is always populated with intentions of the person acting as an agent in a social situation (e.g. Bakhtin, 1986; Wertsch, 1991, 1998). However, in some cases such intentionality can be temporarily inhibited when a person is involved in mechanical sequences of action that have to be performed without any consciousness of what is intended to be achieved, as if it was performed by memory. In these cases, repetition and reproduction of 'previously developed and mastered behavioural patterns' take place (Vygotsky, ibid, p. 7). In contrast, when humans act combining elements, sometimes using previously created artefacts and patterns of behaviour, sometimes suggesting new things through the use of imagination and fantasy, then we can call this a creative process.

This author highlights the mental and emotional aspects 'living within the person', that then are revealed as part of the creative act. Although many creative acts can be thought as solitary constructions of new perspectives and conceptualisations of reality, it is also true that in many cases creativity is carried out as part of a social process in which participants are involved in joint activities that demand of them new ways of addressing a problem and suggesting solutions; for instance, the collaborative construction of a web page, or any other electronic document. Thus, in the context of the study of literacy as a social practice, I would suggest that creativity is a pervasive process of designing situated meanings, in new ways, carried out by agents with intentions, addressing other participants and seeking to reach a goal, either individually or collectively. 


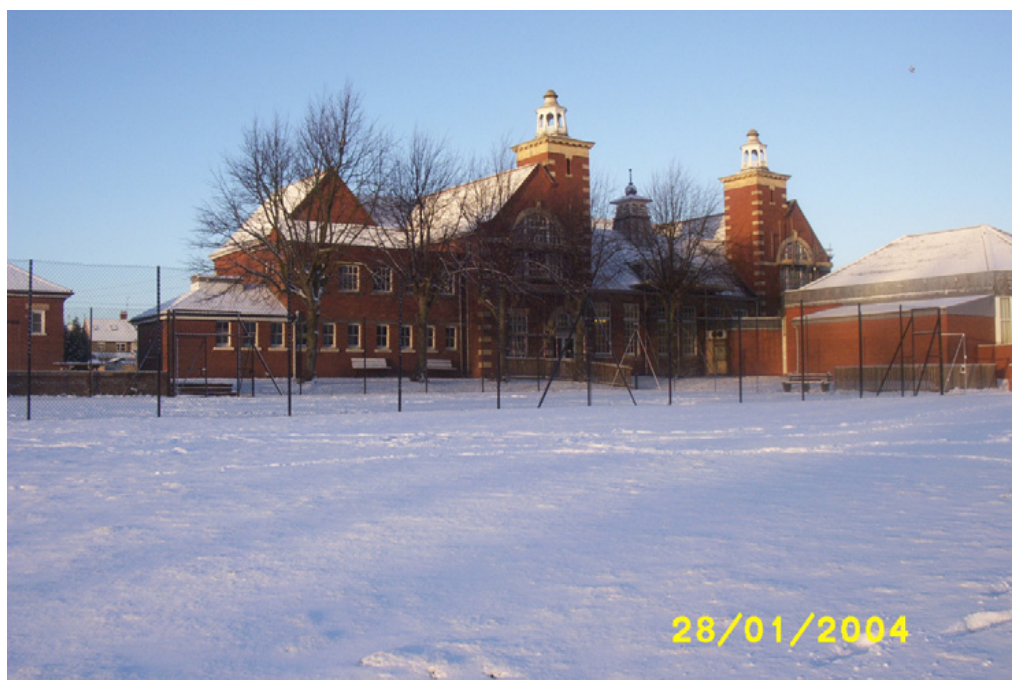

Fig. 1. Primary school in a 'new town' in South East England.

\section{Situated activity systems}

Defining what literacy is, and what to do with the practice of literacy in relation to ICT has become a major issue in education. Similarly, students are faced with an increasing challenge for the creative design of meanings in collaborative situations, with the affordances of multiple modes of representation and in relation to curricular knowledge. The research agenda seems to be mainly related to the description of the changes that the introduction of ICT has produced in the different activities associated with literacy and the related challenges for creativity and design posed for learners. However, I would argue that such descriptions need to account for the different cognitive and communicative processes of participants, as well as detailing the relationship with the sociocultural context in which these practices take place. In other words, it is important not only to provide a description of events in which reading and writing are associated with the use of ICT tools, but also to provide an account of the tools involved in those events as well as the dialogues used by participants to creatively construct meaning in situated action. That is, the challenge is to find a perspective to carry out research studies capable of documenting the relationship between mind, language, context, tools, and design in situated literacy events.

One way in which this methodological challenge can be met is by conceptualizing literacy as a practice embedded in a 'situated activity system'. Following Goffman (1961) and Goodwin (1997), Säljö (1995) has characterised a situated activity system as a 'socially purposeful and situated activity which is maintained through practices that integrate physical tools and instruments, communicative (including cognitive) activities, rules, and traditions of participant roles and contributions, and criteria of success and failure' (p. 92). For instance, Goodwin (1997) has looked at how the interpretation of apparently universal categories such as 'black' can only be achieved by means of the co-construction of local meanings of that colour (e.g. 'jet black') by participants in a situated activity system (e.g. a geochemistry lab and associated practices), who perform asymmetric roles (e.g. an expert researcher and a novice student). Similarly, Goodwin and Goodwin (2000) investigated how girls playing hop scotch built actions that required the integrated use of both particular language formats and the semiotic field provided by the hop scotch grid, which shapes and defines actions being contested (p. 240). By doing that, these authors described dispute processes and forms of social exclusion in the peer group.

Situated activity systems are related to an anthropological and ethnographic stance where participants negotiate positions and identities as members of social groups, as well as privileging an emic standpoint for revealing their own perspective. That is, situated activity systems represent a space to document how participants manage to show their understanding of a situation to each other in interaction. Next, I will describe how I used this approach to investigate:

(a) How did children interpret their involvement in the collaborative construction of web pages?

(b) How the construction of web pages was interactionally accomplished?

(c) How can creativity be identified in interaction?

\section{Characteristics of the study}

A class of Year-4 students participated in a set of sessions constructing collaboratively web pages in two historical themes related to the Victorian era in the UK: 'How life was for children in Victorian times' and 'Victorian famous characters and inventions'. The study took place in a primary school ICT classroom in a 'new town' in South East England, United Kingdom (see Fig. 1 below).

The community is one of the oldest of the area and also one of the most culturally diverse, including an important proportion of students from Pakistani and Indian origin (see Fig. 2). The teacher was young and enthusiast about participating 


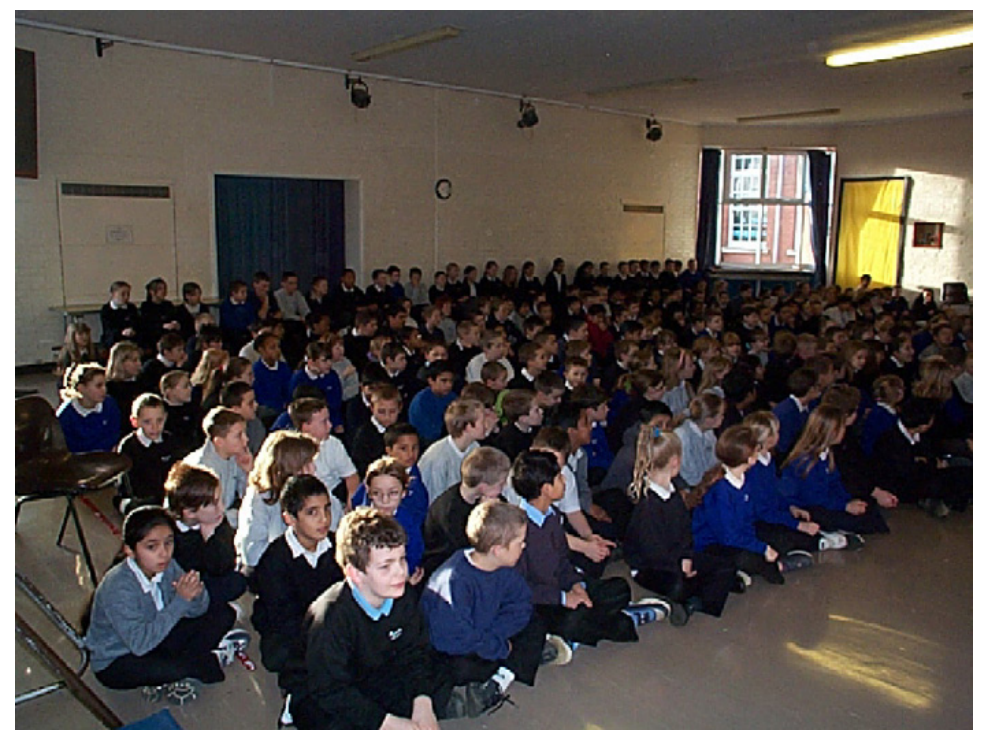

Fig. 2. Community of students.

in this study. She was also keen about the use of ICT tools in schools. However, and despite having this goal set as part of the English Curriculum, she had never constructed a web page with her class of students. Thus, she also welcomed this experience as an opportunity to develop new skills in her career.

\subsection{Participants}

Twenty-three Year-4 students, 9-10 years old worked in groups of 3 in the collaborative construction of web pages for particular History topics, in 11 1-h weekly sessions (see Fig. 3 below). The teacher was also one of the main participants leading the activities through plenary sessions, the 'scaffolding' of small groups, and the provision of general advice about the different tasks that children were involved in. In this sense, the teacher addressed continually issues of multimodal design, historical content, and collaboration skills. I was a participant observer during all the lessons, filming and audio recording all the activities and taking field notes of relevant events. I was also providing mostly technical assistance about the use of the software to create the web pages, together with helping the children in small groups when my assistance was required.

\subsection{Tools}

The main tools used by children and teacher to construct web pages in this situated activity system were:

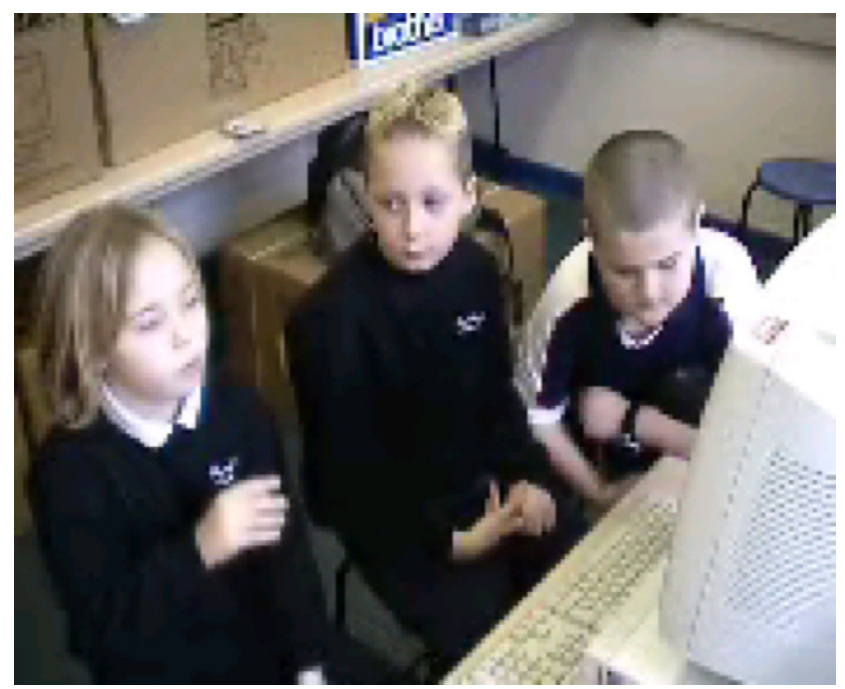

Fig. 3. Small group of students constructing together a web page in History. 
- Projects about the Victorians: Children brought to the sessions historical projects comprising literature reviews about the Victorians.

- Concept maps: Children elaborated a concept map about the Victorians that was brought to the sessions to inform the construction of the web pages.

- Books: The ICT classroom where the study took place had a small library about the Victorians.

- Activity cards: Five activity cards were used by the children in small groups in order to help them to understand how to use software to construct their web pages.

- Software 'SiteCentral' (Cochard et al., 1999): A user-friendly programme to create web pages by dragging and dropping elements from tabs organized in a menu.

- Software 'eMindMaps' (MindJET, 1999): Software used in a couple of lessons to produce an electronic version of the concept map of the Victorians to inform the design of their web pages.

- Victorian clipart library: A Victorian clipart library was created and installed as a 'gallery' in one of the tabs, based on a special school clipart CD-ROM (Cornforth \& Harper, 2001), and on pictures that were taken from the Internet in sites such as the British Museum, the National Portrait Gallery, etc.

\subsection{Data collected}

As with any other project informed by an ethnographic perspective, the data collected comes from several sources:

- Thirty-seven web pages constructed by the children in two related historical themes (published in http://www.geocities.com/jmferc):

- How life was for children in Victorian times (17).

- Victorian famous characters and inventions (20).

- Whole class and small-groups activities: Two focus groups were video recorded ( $20+\mathrm{h}$ of recordings).

- Focus group's ScreenCam files (Lotus, 1998) per session: This software recorded all the activities that children carried out in the screen of the computer, and was analysed in conjunction to the video recording of the children working around the computer in order to make sense of the discourse of the participants in relation to the task.

- Interviews with all children in groups and teacher ( $5+\mathrm{h}$ of recordings): Immediately after the sessions finished I carried out semi-structured interviews, lasting approximately 20-30 min each, with the teacher and the students.

- Field notes were elaborated after every session: They were also reformulated and enriched with the analysis of the video recording of the sessions and the identification of different communicative events that took place during the project in plenaries and small-group activities.

- Group responses to activity cards: As part of the use of the activity cards, children were often asked to write down information in them in relation to their appropriation of the design principles for the construction of web pages. (See Appendix A).

- Paper and electronic concept maps: Two of the key products of the project.

- Other sources: E-mails with teacher, thank-you-cards, etc.

\section{Analytical framework}

As part of the field of ethnography of communication (Hymes, 1974; Saville-Troike, 2003) that informs this project, Hymes (1972) has defined the existence of a nested hierarchy of units of analysis that he called: communicative (or speech) situation, communicative event, and communicative act. Thus, in this hierarchy communicative acts are part of communicative events, which are, in turn, part of communicative situations. More specifically, a communicative situation is 'the context within which communication occurs'. It is not always subject to a given location, and maintains a 'general configuration of activities, the same overall ecology which communication takes place, although there may be great diversity in the kinds of interaction which occur here' (Saville-Troike, 2003, p. 23). Examples include ceremonies, court trials, fights, holiday parties, hunts, lovemaking, and a lesson in a school. According to Hymes, communicative situations are composed of speech and other kinds of events. They are not themselves subject to rules of communication, although rules of communication may refer to these situations as contexts (Fasold, 1990, p. 42).

Communicative events are both communicative and governed by rules of speaking. A communicative event takes place within a communicative situation and is composed by at least one speech act. According to Saville-Troike:

A single [communicative] event is defined by a unified set of components throughout, beginning with the same general purpose of communication, the same general topic, and involving the same participants, generally using the same language variety, maintaining the same tone or key and the same rules of interaction in the same setting (Saville-Troike, 2003, p. 23).

Examples of communicative events are categories of talk such as conversations, lectures, or formal introductions. However, some events are not as clearly defined with social labels, and in this respect their identification constitutes a fundamental part of applying the ethnography of communication. 
Finally communicative (or speech) acts, are identified by its 'single interactional function, such as a referential statement, a request or a command, and maybe either verbal or nonverbal' (Saville-Troike, 2003, p. 24). Also, according to Fasold (1990) a communicative or speech act in the area of the ethnography of communication has a slightly different meaning to the concept of speech act as defined in philosophy and pragmatics. Thus, in the case of the ethnography of communication 'a speech act gets its status from the social context as well as from the grammatical form and intonation', and can be constituted by more than one utterance (p. 43). For example, a joke (communicative act) that is embedded in a conversation (communicative event) within a dinner party (communicative situation) can be constituted by several speech moves, in the same way that greetings (communicative act) usually are made of pairs of conversational moves.

\section{Communicative events}

By using the tapes recorded during the project of the whole class plenary sessions and the two focus groups, and also by using the corresponding ScreenCam files for each of the focus groups and the information collected and registered in field notes, the $20+\mathrm{h}$ of video recording were codified in NVivo (QSR International, 2002) in terms of 'communicative events' as units of analysis. In this respect, I found the following:

- Forty-one different types of communicative events identified and coded. A node was created in NVivo to codify the occurrence of each event. For example: 'Typing captions' was one of the types of communicative events identified that was defined as 'This node codifies instances where children write captions to images'.

- Five hundred and ninety one communicative events were coded in total. For instance, in the example provided above, 'Typing captions', this event was identified in five occasions in the recording of the focus groups. Communicative events were mostly defined by the actions of the participants as single-goal processes. However, in many cases several goals were pursued at the same time. Thus, types of events were mostly mutually exclusive, although multiple coding was allowed to be able to account for the possibility of having a communicative event serving several purposes in parallel or transitions between goals, such as writing a draft in paper and typing a caption simultaneously; or a plenary where the teacher addressed issues of design that were intertwined with the explanation about the use of certain commands in the software (e.g. the node of 'plenary design' overlaps with 'plenary software' in some moments).

\section{Analysis}

Hymes (1972) proposed that in order to understand how a communicative event is structured it is necessary to identify its components and the relationships amongst these components so we can provide a comprehensive ethnographic account of such events and their rules of speaking. Hymes's starting point for elaborating an inventory of the relevant components to be identified in communicative events is the list of Jakobson's factors of communication (Jakobson, 1960). Elaborating Jakobson's model, Hymes proposes the following 16 components:

(1) message form;

(2) message content;

(3) setting;

(4) scene;

(5) speaker or sender;

(6) addressor;

(7) hearer, or receiver, or audience;

(8) addressee;

(9) purposes-outcomes;

(10) purposes-goals;

(11) key;

(12) channels;

(13) forms of speech;

(14) norms of interaction;

(15) norms of interpretation; and

(16) genres.

Thus, the rules of speaking determining a given communicative event would be stated in terms of relationships amongst these components, perhaps prioritising some of them depending on each communicative event and the social group where any event takes place. For instance, there would be social groups where 'rules of speaking will be heavily bound to setting; for another primarily to participants; for a third, perhaps to topic', (p. 66).

Next I will present a sequence where I will be focusing on some of Hymes's components, along with other concepts that I will describe in turn, to analyse the intrinsic collaborative and creative nature of the construction of knowledge as part of the use of language by primary school children in the UK while constructing web pages in small groups. 


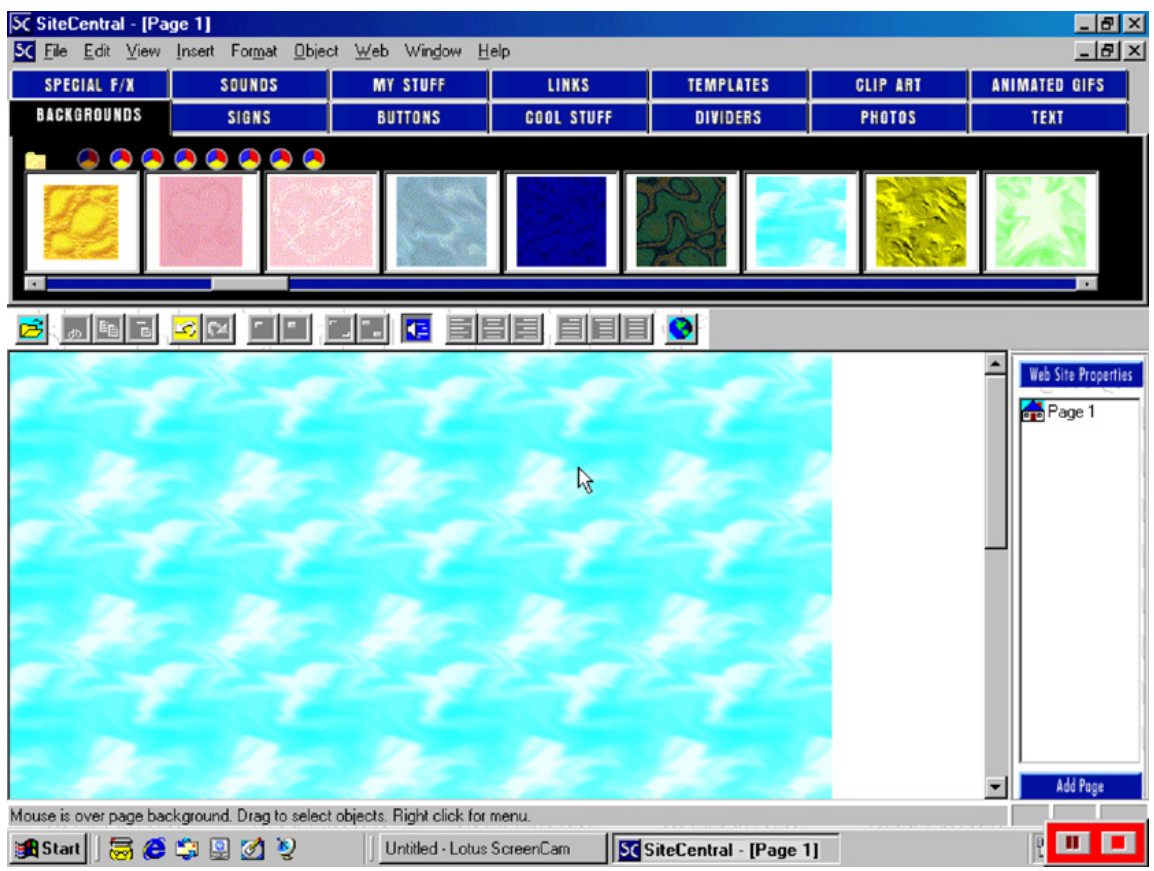

Fig. 4. Background of clouds.

\subsection{The collaborative and creative nature of the construction of knowledge}

In this section I shall illustrate the intrinsic cooperative and creative nature of the construction of knowledge. To do so, I will use Hymes's model of components of communicative acts, focusing on the components of purposes-goal and purposesoutcome. Also, I will draw on the claims about the intrinsic cooperative nature of communicative events as discussed by Linell (1998) and Maybin (1996).

The following transcript represents an example of the communicative event of 'choosing backgrounds', carried out by dragging and dropping this visual element into the blank space of the screen to create a web page, and the dialogue around this event. The transcript starts when the children have been asked to start working on a new web page. Children were provided with an activity card (see Appendix A) in each session designed to:

(a) helping them with some software commands,

(b) providing a structure for the task by prompting them to write down specific information, and

(c) describing the steps that needed to be followed to continue working on the construction of their web page.

Thus, by this point of the session they have been reading together the first page of this activity card that has just asked them to write down how the background for their new web page will look:

\subsubsection{Transcript 1. Clouds}

1 Annie: OK. So. 'The colour of the background will be'. (Reading from the activity card). What colour do you want it to be?

2 Nancy: You just go through (the background tab).

3 Annie: Yeah, just go through? Yeah? Jake? Scroll them all. //It will be an introduction sort of background.

4 Jake: I say the one we did last time, cos it's about smiley faces.

5 Nancy: Which one?

6 Jake: Erm, keep on going.

7 Annie: Ooh, we did the clouds.

8 Jake: No, we were gonna do the clouds.

9 Annie: Shall we do the clouds or not?

10 Nancy: OK.

11 Annie: Try the clouds?

12 Jake: Yeah.

13 (4 sec. Dragging and dropping the background onto the blank page) (Fig. 4).

14 Nancy: These are the clouds. Shall we see if there's anything else?

15 Annie: Yeah. Go on. //Hiiiiim! Love hearts, love hearts. Please!!! (Fig. 5)

16 Nancy: Which one? (Pointing with the cursor) Yeah? 


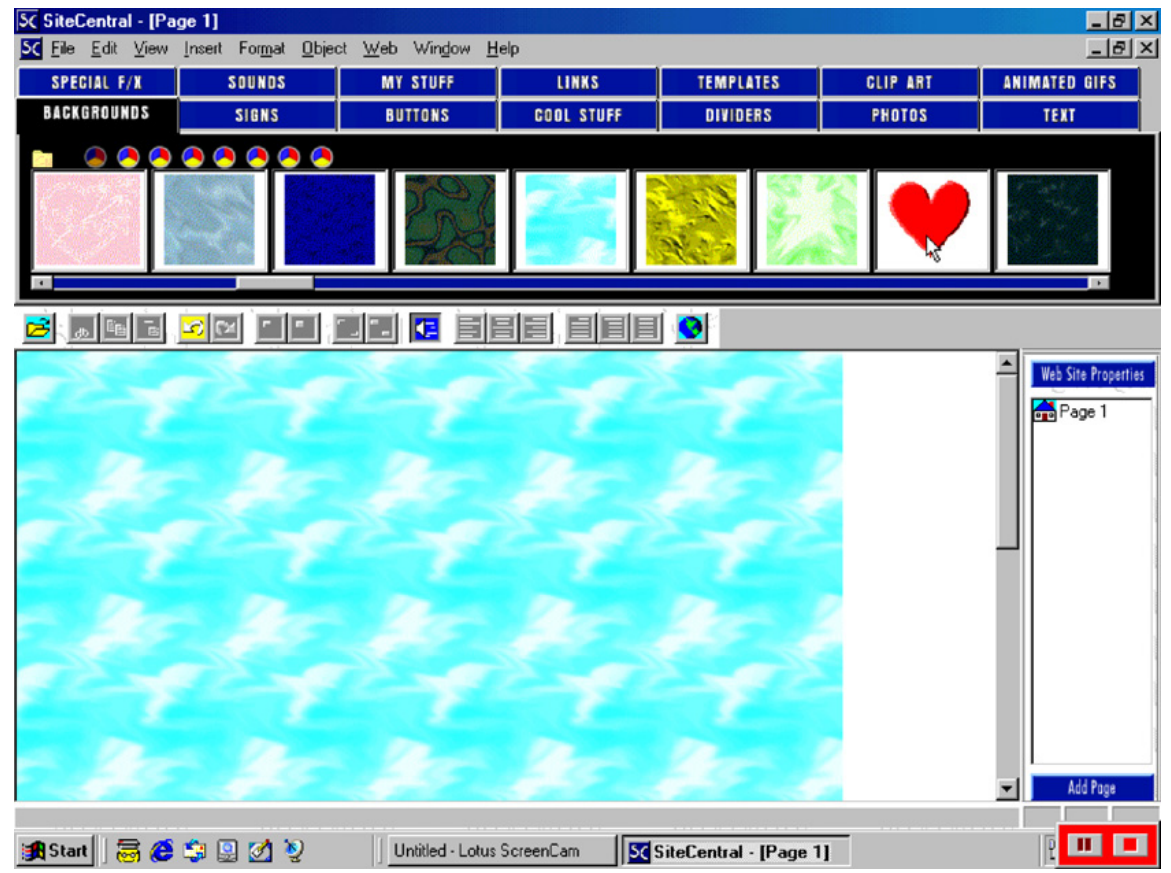

Fig. 5. Nominating a background of hearts.

17 (Jake shaking head. Annie dragging and dropping a background of pink patterns on the blank page) (Fig. 6).

18 Nancy: No, actually no.

19 Annie: No //[Let's have a look to ... it's an introduction ...

20 Jake: [You know there's a boy here, so, NO hearts.

21 Annie: No, no, no, it's an introduction. What about just a plain colour?

22 Jake: Why?

23 Annie: Cos that's the sort of colour you have in a background.

24 Nancy: We are actually doing about. What is she?

25 Annie: Florence Nightingale. She's a famous nurse, but we are doing an introductory, an introductory paragraph. 26 Nancy: A heart, cos she done hearts, she took hearts out.

27 Annie: She did, I think. She did.

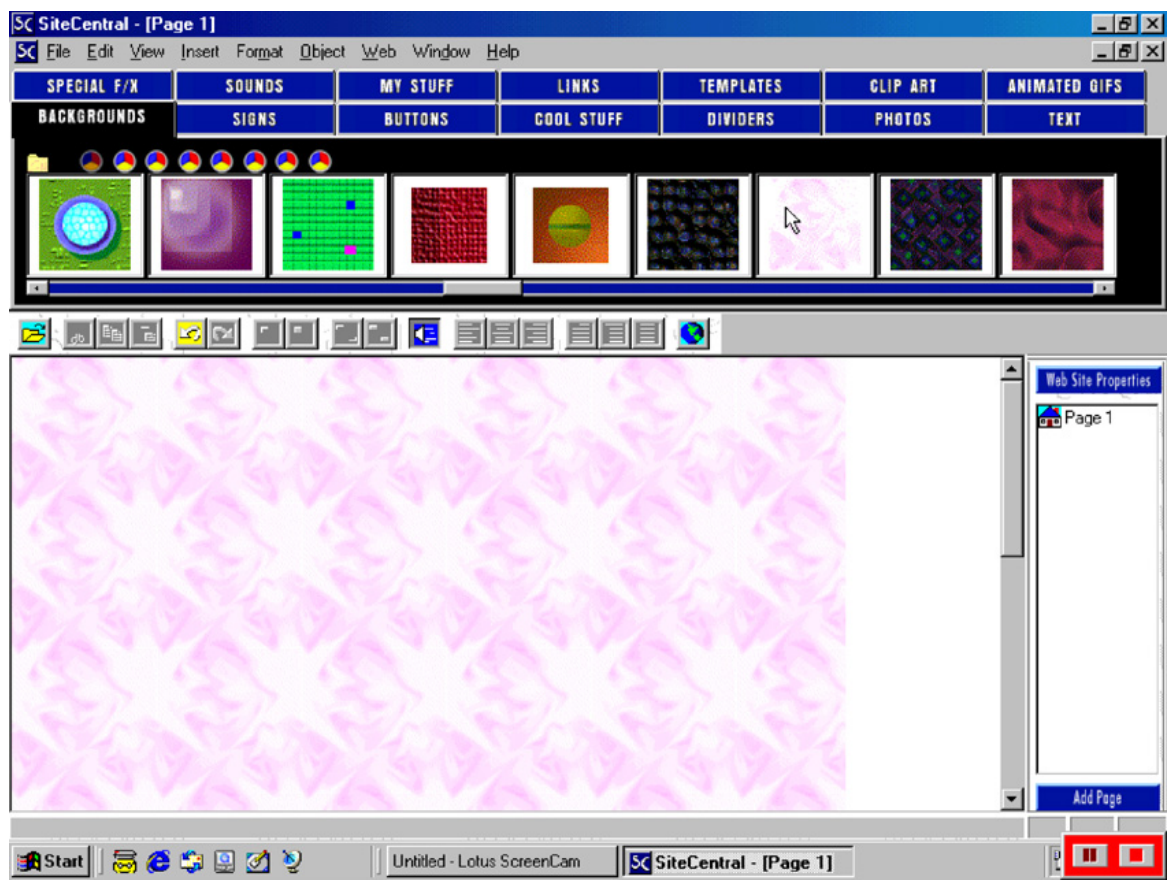

Fig. 6. Background of pink patterns. 


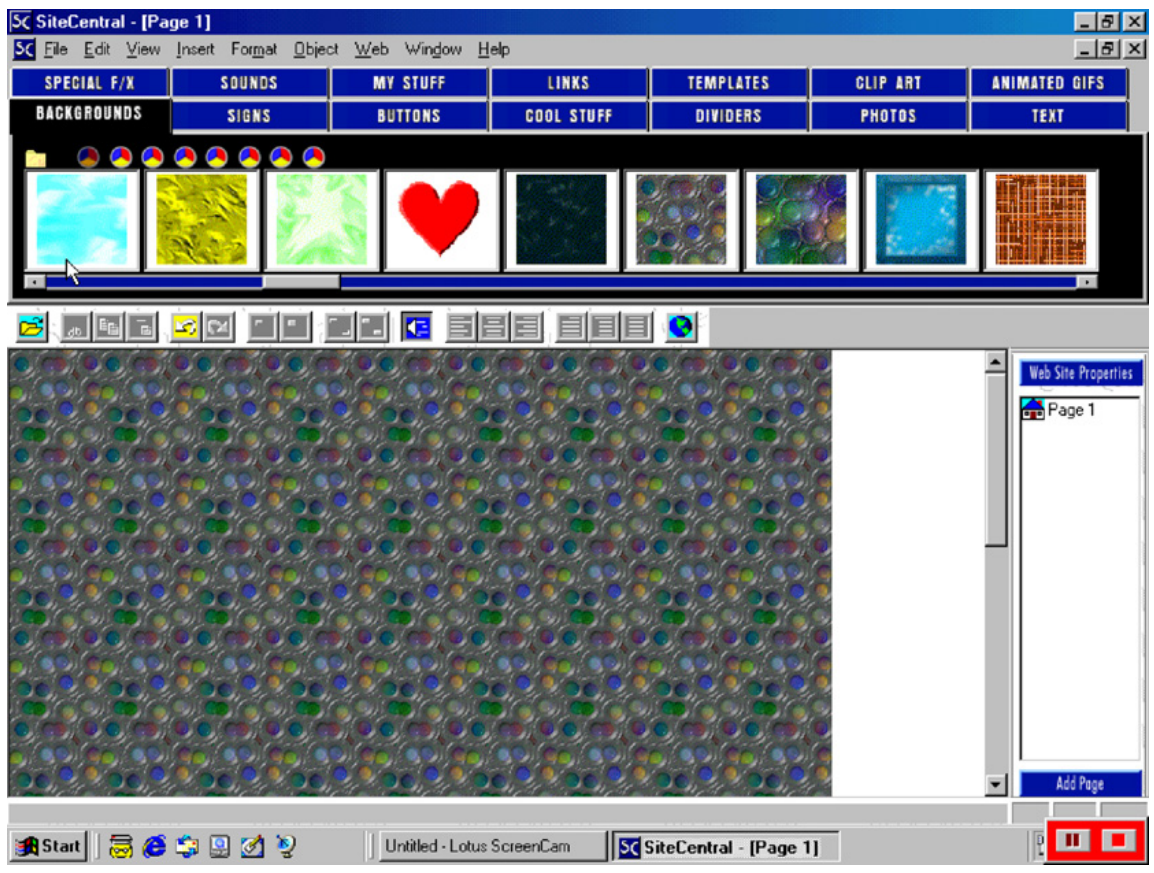

Fig. 7. Background of small circles.

28 Jake: Yeah, but that's a lot of hearts when you put that on.

29 Annie: No smiley faces. People weren't happy on those times.

30 Jake: Yeah.

31 Annie: Three hundred and fifty five million people died.

32 Jake: They'd be happy for Queen Victoria (pointing the screen, to a group of posh Victorian people?)

33 (Annie laughing)

34 Nancy: just tell me when I stop (Nancy is clicking looking for backgrounds).

35 Annie: Stop! That one (pointing to a background).

36 Jake: Noooo.

37 Annie: I want to see what it is, really badly. (They drag and drop the following background) (Fig. 7).

38 Annie: Noooo!

39 Nancy: I want to go back to the clouds.

40 Jake: No, just keep on going.

$41 \mathrm{~T}$ : Colours. What kind of colours will you choose? (Teacher helps them to choose the background of clouds).

The resulting page they constructed at the end of the session is shown in (Fig. 8) below:

\subsubsection{Commentary}

Hymes (1972) described the ends of a communicative act as purposes-outcomes and purposes-goals. Whereas purposesoutcomes refer to the 'conventionally recognized and expected outcomes' from a community standpoint (such as a decision, a settlement, or a legal ruling), purposes-goals refer to the strategies of the participants pursuing different goals within the expected outcome of a communicative event (p. 61). That is, any communicative event requires a basic compromise of the participants to a shared goal in order to take place. In other words, according to Linell (1998), communicative events require at least 'a perfunctory cooperation, even if the participation is based on complimentarity rather than symmetry'. Thus, all communicative events 'must be (partially) shared, at least in the sense that they involve both the speaker and her interlocutor(s); parties are mutually other-oriented', (p. 225).

In the transcript, the goal of the event is prompted by the activity card that is mediating the efforts of the children in the task, as they are reading in utterance 1: Annie: 'OK. So. The colour of the background will be.' (Reading from the activity card). The reading of this section of the activity card prompts Annie's request in this respect: 'What colour do you want it to be?' This is elaborated further in utterances 2 and 3 as to get an agreement of how they will proceed to choose their background by scrolling along the backgrounds tab (e.g. 3. Annie: 'Yeah, just go through? Yeah? Jake? Scroll them all.'). From there, several backgrounds are tried dragging and dropping them onto the blank page of the programme (lines 13, 17, 37, 41). Several criteria (e.g. 3. Annie: ... 'It will be an introduction sort of background.') and reasons are provided to support (e.g. 4. Jake: 'I say the one we did last time, cos it's about smiley faces'; 26. Nancy: 'A heart, cos she done hearts, she took hearts out') or reject each of them (e.g. 20. Jake: 'YYou know there's a boy here, so, NO hearts'; 21. Annie: 'No, no, no, it's an introduction. What about just a plain colour?'). However, sometimes, it was just a matter of trying the outcome of dragging and dropping each background 


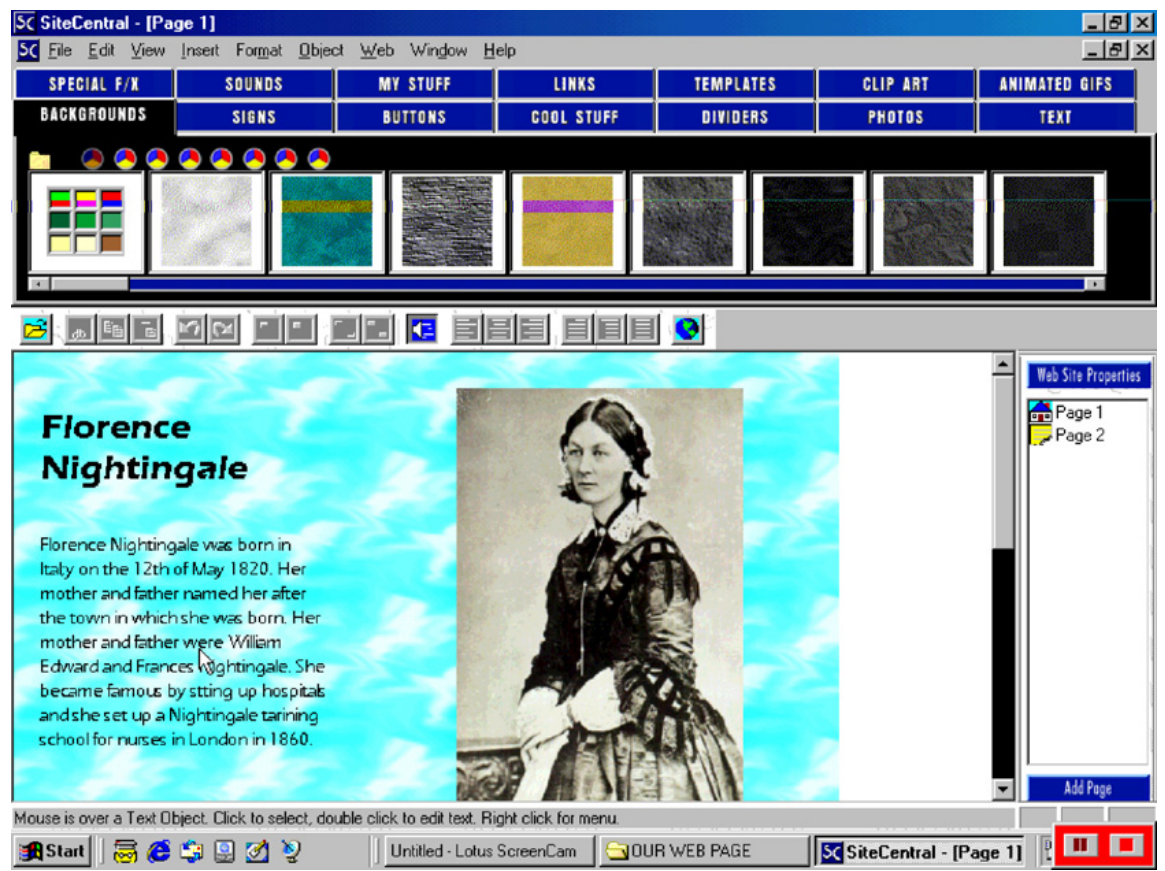

Fig. 8. Web page about Florence Nightingale.

(e.g. 11. Annie: 'Try the clouds?'; 14. Nancy: 'These are the clouds. Shall we see if there's anything else?'). In any case, they were linked to the existence of a common outcome being pursued by the children that in some occasions was explicitly reiterated (25. Annie: 'Florence Nightingale. She's a famous nurse, but we are doing an introductory, an introductory paragraph.').

In sum, backgrounds were tried one after the other, and the children elaborated on the suitability of each of them for the purpose of the web page (e.g. 21. Annie: 'No, no, no, it's an introduction. What about just a plain colour?'), until one option got stabilised (e.g. the background of the clouds). In other words, children seemed to be adjusting their interventions to the communicative needs of this event.

Knowledge was creatively constructed as part of this process, where different layers of contextual references interacted with each other. In this transcript we see how elements of the physical context triggered the mention of historical concepts linked to them, as if the elements present in the context of the activity were 'framed' in different ways, thus reshaping continually the context of the situation where children were involved (e.g. see Goffman, 1974; Maybin, 1996, pp. 143-145; Maybin \& Swann, 2007). For example, I would suggest that the mention of the possibility of using a background of hearts interpreted perhaps as a 'girly' preference by Jake (e.g. 20. Jake: '(You know there's a boy here, so No hearts.'), is contextualised as a historical fact by Nancy in utterance 26 mentioning that Florence Nightingale did take hearts out as a nurse. However, the situation is framed back again by Jake in utterance 27 in the context of the background contested as a non-neutral graphic element when he says 'Yeah, but that'a a lot of hearts when you put that on', implying that this is not a faithful representation of Florence's job. Similarly, in utterance 29 Annie challenges the possibility of using a background of happy faces as it is a historical contradiction for the Victorian times when 'people weren't happy on those times' and elaborating in utterance 31 about the fact that 'three hundred and fifty five million people died'. Yet again, in utterance 32 Jake contests Annie's perspective by reframing her argument pointing to a picture with a group of posh people mentioning that certainly 'they'd be happy for Queen Victoria'.

Thus, the dialogue of the three children can be seen as a creative construction of knowledge without the need of being completely explicit. This is possible in terms of a process of framing interventions that can always be presented or interpreted in more than one way: e.g. as a "girly" preference, as a neutral graphic element, as a historical fact, etc.

\section{Creativity in communication}

Following a sociocultural perspective to applied linguistics Maybin and Swann (2007) propose an analytical approach integrating three dimensions to the analysis of creativity:
(a) textual,
(b) contextual, and
(c) critical.

The textual dimension corresponds to the intrinsic properties of texts including patterns and linguistic features of genres. In this respect, the transcript analysed above shows that students used a number of figures of speech such as hyperbole, thus 
exaggerating for emphasis (26. Nancy: 'A heart, cos she done hearts, she took hearts out' or 31. 'Three hundred and fifty five million people died'.). Similarly, I identified other creative uses of language in communicative events such as irony, imaginative play with shared knowledge, puns and wordplay. For instance, in a communicative event where children were reading together aloud, I found:

\subsection{Excerpt 1}

(9) Claire: You want to read, you want to read a little bit?

(10) Kieran: Yeah. 'At the ...

(11) Claire: End, (pointing the screen following the paragraph with the finger)

(12) Kieran: Eh? end, of, the

(13) Claire: Eightee ...

(14) Kieran: Eighteen

(15) Claire: cen ...

(16) Zahir: century

(17) Kieran: eh?

(18) Claire: cen ...

(19) Zahir: century

(20) Claire: cent, tu, ry (Claire moves her finger following the shape of the letters on the screen in the next turns)

(21) Zahir: a

(22) Kieran: A man called

(23) Claire: Rob

(24) Zahir: Robert De Niro

(25) Claire: shh, ssh, ssh

(26) Kieran: Ra

(27) Claire: Rai, kes,

In the previous event it is interesting to see the word play between Robert De Niro and Robert Raikes. The first character is a Hollywood star and the second was a Victorian philanthropist who supported Sunday Schools; these schools were set up as an option for working children in factories who were not allowed to go to school from Monday to Saturday. The play between the two characters is also useful to identify how empathy is being constructed amongst the participants. That is, Claire and Zahir are trying to help Kieran to read, and the joke in turn 24 is helpful to relief the possible stress the situation is creating for Kieran who does not seem to be able to read as fast as Zahir might want.

For Maybin and Swann (ibid.), the contextual dimension draws on the analysis of context as the sociohistorical and interactional frames of reference used by participants to situate meaning in interaction. In this respect, in the transcript analysed above it is quite evident how gender framing through the use of symbols which are evidently feminine, such as hearts, are contested by the boy in line 42 (Jake: [You know there's a boy here, so, NO hearts.).

Likewise, in a different event, the teacher and pupils were involved in a plenary session in the classroom as follows:

\subsection{Excerpt 2}

$1 \mathrm{~T}$ : Right. In a minute, I will welcome you to my latest game show

2 Class: wow! oooh!

3 T: This game show

4 David: is called

5 T: Is called: 'My life as a web page reviewer'

6 Class: hum?

7 T: What's a reviewer?

8 Child: somebody that $(. .$.

9 T: Well done. Somebody (...) Somebody who reviews, looks at something, thinks about, decides what they think about it, do they like it, do they not like it, why, what looks good, what doesn't look good, what do they enjoy, what caught their attention ... All those kind of things are all to do with reviewing a web page. OK? And I'm giving you just, one minute, to have a wander around, look at other people's web pages, you can click on their different pages, see how much they've done, and them come back. Off you go. Go and have a wander.

In the previous excerpt the teacher transforms the context of the classroom into a TV game show; thus, creatively changing the participation framework into a contest where students display their knowledge and expertise as members of an imagined community of web page reviewers.

Finally, for Maybin and Swann, the critical dimension refers to the assessing or evaluative stance taken by participants towards what is being negotiated and its resulting positioning. In this dimension, in the transcript above it is evident not only how children continually evaluate the symbols being invoked as candidates for design (i.e. hearts), the positions they 
take as boy and girls, but also their judgement about the quality of life in Victorian times (42. 'Annie: No smiley faces. People weren't happy on those times'.).

Similarly, in another event where children were choosing different pictures to illustrate their web page, I found:

29 Claire: Ahh! cool! // that's a Victorian there ... that's what it is. (Drags and drops in the background the picture of a person, dressed with old traditional clothes).

30 Zahir: These are like Victorians. (Pointing to a picture of a group of people dressed in modern clothes).

31 Claire: These aren't. Victorians are like posh people.

32 Zahir: Yeah, that's you Kieran. You're posh.

33 Claire: And now we need a ragged person.

In this excerpt it is interesting to see how children evaluate Victorians as posh people, not only displaying their knowledge of the distance between social classes in nineteenth century England (i.e. posh people vs. ragged person), but also positioning themselves in this context. That is, although Kieran wears modern clothes, Zahir labels him as posh in turn 32 . We could also contrast this explicit positioning with the implicit position of Claire as a knowledgeable person who re-defines for the group what can be considered Victorian and what is not, as she mentions in turn 31: Claire: These aren't. Victorians are like posh people.

\section{Conclusion}

Literacy has undergone a profound changing process with the introduction of ICT, posing associated challenges for creativity education and research. As educational researchers we are also facing many simultaneous challenges to be addressed, such as providing insights into how students can better learn to read and write multimodal electronic documents in different areas of the curriculum, in collaboration with others, and in a creative manner. We also need to be able to explain how literacy events are related to context, culture and communication. In this paper I have suggested that one productive way to face these challenges is by using an ethnographic approach to communication and to the analysis of creativity in situated activity systems. Following this proposal, I mapped the different tools constituting the situated activity system and categorised the different communicative events that took place within such system. Then I analysed how creativity was an inherent part of the collaborative construction of web pages in History in situated events.

Moreover, in this paper I addressed the following research questions:

\section{1. (a) How did children interpret their involvement in the collaborative construction of web pages?}

Although this was not a professional 'design community', I gathered evidence of the participants' efforts to become members of a community of practice designing web pages. This system evolved rapidly from a set of tools, institutional rules, and goals defined as part of a multimodal literacy programme, into a community with a social configuration where specialised subject positions and roles were identified by participants, even if these were not fully developed because of the short period dedicated to this programme. By focusing on the perspective of participants during the analysis I was able to illuminate the interactional processes they used to show each other their interpretation of the task and negotiate categories of meaning relevant to their involvement in communicative events. That is, members of this learning community showed their understanding in relation to the way they interpreted the design rules for a multimodal text, the means for working together in collaboration and distributing roles, as well as their interpretation of what counts as historical knowledge.

\section{2. (b) How the construction of web pages was interactionally accomplished?}

Participants negotiated meaning as part of the activity in which they were involved, demonstrating to be communicatively involved with the different tasks within the situated activity system where the web pages were designed. That is, children participated skilfully in communicative events where they were doing a web page, using historical knowledge and working in groups. In the analysis, I showed how in order to be able to participate in a communicative event participants must agree, at least partially, on a shared goal. According to Hymes, and as I have showed in this paper, the components of communicative acts need to be analysed to provide an account of the nature of communicative events and their rules of speaking. In other words, I would argue that any evaluation of whether participants are being effective or not in the way they construct knowledge cannot be only a function of the degree of explicitness of their utterances, but also a function of the degree of their adjustment to the communicative requirements of the situation.

For instance, one of the most recurrent features of this type of communicative events is the heavy reliance of utterances on other modes of communication, particularly in relation to the pointing of visual elements and other tools that are part of the situated activity system. Deictic terms such as 'this', 'that', 'here', 'there', 'it', indicate constantly the exophoric reference to elements in the screen that change rapidly, as well as the cursor of the mouse. These elements are a very important shared visual reference for creative meaning making, and are a common feature of conversations around computer-mediated activities. Therefore, it is important to incorporate more modes of communication within the transcript. Participants construct meanings in multimodal interactions, and it is important to have multimodal transcripts available for the analyst, just as 
these modes are available for participants, in order to identify in the closest possible way the perspective members have within a situation (e.g. see Norris, 2002). Thus, as the reader can notice in this paper, the inclusion of pictures of the screen when the children are working in a moment-by-moment basis provided a very important element of interpretation for the utterances of the children and the recognition of different contextualising factors and frames of reference of the participants for the creative construction of knowledge.

\section{3. (c) How can creativity be identified in interaction?}

In relation to the analysis of creativity features in language use, I showed how participants managed to communicate and negotiate their intentions by using several figures of speech and language games, as well as contextually reframing their positions as participants in a dialogue. Similarly, they took an evaluative stance towards their school knowledge in History showing their understanding to each other. All these interactional moves took place despite the constraints of a participatory framework of a situation defined as a school collaborative task. That is, children and teacher demonstrated their creative abilities in a textual, contextual and critical level, despite not being in an informal scenario. Creativity is possible in formal situations.

Similarly, creativity is not a gifted capacity; it is an everyday act which is interactionally accomplished in the context of social participation as members of a community. Thus, creativity is not only a function of the individual capacity for imagining alternatives and possibilities; it is the result of participation in events where members of a group creatively display their intentions and negotiate new alternatives for the interpretation of actions in situated activity systems. In this context, language use is a social tool for organizing joint action, and how this is interpreted in groups; creative nominations and evaluations are co-constructed in the course of interaction and in relation to the available participatory frameworks available.

Finally, this article contributes to the overall theme of the special issue with the analysis of the construction of knowledge and creativity in the context of language use in literacy practices. It stresses the usefulness and relevance of carrying out studies where creativity is part of the research agenda following an ethnographic approach to communication. In this way, creativity can be studied as a situated aspect of language use.

\section{Appendix A}

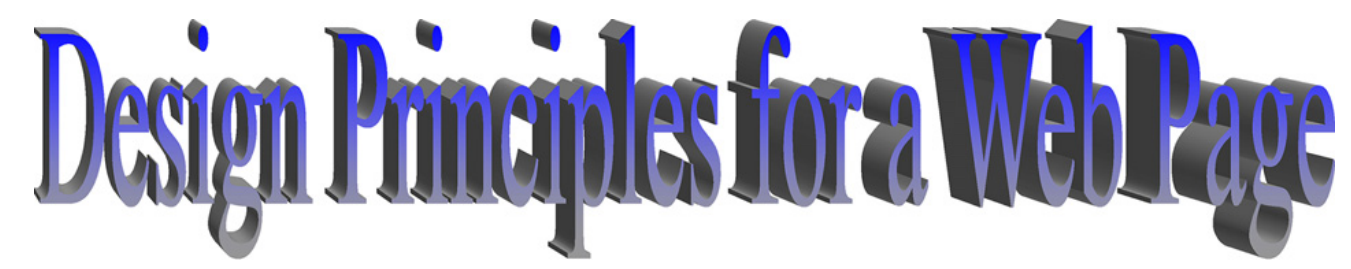

(i) Choose backgrounds and pictures according to the aesthetic standards of Victorian times. For example, Victorians liked wallpaper with patterns based on flowers, plants and birds, so you might use similar patterns for a background. Also, Victorians liked to take photographs with cameras that were just invented at that time. As all the photographs from that period were taken in black and white, you might want to use some of the examples found in the tabs of SiteCentral.

(ii) Sometimes, it is not easy to find exactly a Victorian picture or background. If you do not find them, then you may use other elements who does not contradict the graphic representations of the situations of the Victorian times (e.g. do not put a PlayStation video game representing the "spare time" section).

(iii) Use colours for the fonts that can contrast with the background. For example, if the background is green, you can use red fonts, if the background is purple, you can use yellow fonts; if the background is orange, you can use blue fonts.

(iv) Choose a font according to the Victorian aesthetic standards. The typewriter was invented in 1867, so Victorians liked to write with this new device in fonts similar to the ones we use more frequently in our word processor, like Times New Roman or Courier New, but also some other like $\mathbb{Q I D} \mathbb{E} \mathfrak{E} \mathfrak{d} l i s \mathfrak{s}$ or G D UD Y . However, they used to have a lovely handwriting like this, when they wrote personal letters and reports by hand.

(v) Whenever you write something in the page next to an image, they have to be related to each other meaningfully, by having the text explaining what you can see in the image, and the image representing what is written.

(vi) Try to present an organized menu of choices or links for the reader to have an overview of what can he or she finds in the site.

\section{References}

Bakhtin, M. M. (1986). V. W. McGee, T. C. Emerson, \& M. Holquist (Eds.), Speech genres and other late Essays (p. 8). Austin, TX: University of Texas Press.

Cochard, S., Jordan, D., Horn, K., Wing, J., Chin, B., Carlson, K., et al. (1999). SiteCentral (Version 1. 0) [Windows platform]. El Cajon. California, US: Wagner Publishing Inc.

Cornforth, D., \& Harper, K. (2001). National curriculum clipart [Windows platform]. Huntingdon: Global Software Publishing.

Cowie, H., \& van der Aalsvort, G. (2000). Social interaction in learning and instruction. Oxford: Pergamon.

Craft, A., Dugal, J., Dyer, G., Jeffrey, B., \& Lyons, T. (1997). Can you teach creativity? Nottingham: Education Now Publishing Co-operative. 
Craft, A., Jeffrey, B., \& Leibling, M. (Eds.). (2001). Creativity in education: Current perspectives on policy and practice. London: Continuum.

Dillenbourg, P. (Ed.). (1998). Collaborative learning: Cognitive and computational approaches. Oxford: Pergamon.

Fasold, R. (1990). Sociolinguistics of language Oxford: Basil Blackwell.

Flood, J., Heath, S. B., \& Lapp, D. (1997). Handbook of research on teaching literacy through the communicative and visual arts. New York: Simon \& Schuster Macmillan.

Goffman, E. (1961). Encounters: Two studies in the sociology of interaction. Indianapolis, IN: Bobbs-Merrill.

Goffman, E. (1974). Frame analysis. Harmondsworth: Penguin Books Ltd.

Goodwin, C. (1997). The blackness of black: Color categories as situated practice. In L. B. Resnick, R. Säljö, C. Pontecorvo, \& B. Burge (Eds.), Discourse, tools and reasoning (pp. 111-140). Berlin: Springer-Verlag.

Goodwin, M. H., \& Goodwin, C. (2000). Emotion within situated activity. In A. Duranti (Ed.), Linguistic anthropology: A reader (pp. 239-257). Malden, MA, Oxford: Blackwell.

Heath, S. B. (2000). Seeing our way into learning. Cambridge Journal of Education, 30(1), 121-132.

Hornby, A. S. (2000). Oxford advanced learner's dictionary (6th ed.). Oxford: Oxford University Press.

Hymes, D. (1972). Models of interaction in language and social life. In J. J. Gumperz \& D. Hymes (Eds.), Directions in sociolinguistics: The ethnography of communication (pp. 35-71). London: Basil Blackwell.

Hymes, D. (1974). Foundations in sociolinguistics. London: Tavistock Publications Limited.

Jakobson, R. (1960). Closing statement: Linguistics and poetics. In T. A. Sebeok (Ed.), Style in language (pp. 350-377). New York: Wiley.

Jewitt, C., \& Kress, G. (2003). A multimodal approach to research in education. In S. Goodman, T. Lillis, J. Maybin, \& N. Mercer (Eds.), Language, literacy and education: A reader Stoke on Trent (pp. 277-292). Trentham Books.

Kress, G., \& van Leeuwen, T. (1996). Reading images: A grammar of visual design. London: Routledge.

Labbo, L. D. (1996). A semiotic analysis of young children's symbol making in a classroom computer center. Reading Research Quarterly, 51, $356-385$.

Labbo, L. D., \& Kuhn, M. (1998). Electronic symbol making: Young children's computer-related emerging concepts about literacy. In D. Reinking, M. C. McKenna, L. D. Labbo, \& R. Kieffer (Eds.), Handbook of literacy and technology: Transformations in a post-typographic world (pp. 79-92). Mahwah, NJ: Lawrence Erlbaum.

Leu, D. J., Jr., \& Kinzer, C. K. (2000). The convergence of literacy instruction with networked technologies for information and communication. Reading Research Quarterly, 35(1), 108-129.

Linell, P. (1998). Approaching dialogue: Talk, interaction and contexts in dialogical perspectives. Amsterdam: John Benjamins.

Lotus. (1998). Lotus ScreenCam (Version Windows 95) [Windows platform]. Staines: Lotus Development Corporation.

Maybin, J. (1996). Children's voices: The contribution of informal language practices to the negotiation of knowledge and identity amongst 10-12 year old school pupils. Unpublished PhD, The Open University, Milton Keynes.

Maybin, J., \& Swann, J. (2007). Everyday creativity in language: textuality, contextuality and critique. Applied Linguistics, $28(4), 497-517$.

Mayer, R. E. (2000). The challenge of multimedia literacy. In A. W. Pailliotet \& P. B. Mosenthal (Eds.), Reconceptualizing literacy in the media age (pp. 363-376). Oxford: JAI Press Inc./Elsevier Science.

MindJET. (1999). eMindMaps (Version 2.0.7) [Windows platform]. Sausalito, CA: MindJET LCC.

Norris, S. (2002). The implication of visual research for discourse analysis: transcription beyond language. Visual Communication, 1(1), 97-121.

Pearsall, J. (1998). The new oxford dictionary of english. Oxford: Oxford University Press.

QSR International. (2002). QSR NVivo (Version 2.0.161) [Windows platform]. Doncaster, Melbourne: QSR International Pty. Ltd.

Rassool, N. (1999). Changing definitions of 'text' within the information society. In N. Rassool (Ed.), Literacy for sustainable development in the age of information (pp. 155-183). Clevedon: Multilingual Matters.

Reinking, D. (1994). Electronic literacy. Perspectives in Reading Research, 4, 1-17.

Rojas-Drummond, S. M., Mazón, N., Fernández, M., \& Wegerif, R. (2006). Explicit reasoning, creativity and co-construction in primary school children's collaborative activities. Thinking Skills and Creativity, 1(2), 84-94.

Säljö, R. (1995). Mental and physical artifacts in cognitive practices. In P. Reimann \& H. Spada (Eds.), Learning in humans and machines: Towards an interdisciplinary learning science. Oxford: Pergamon.

Saville-Troike, M. (2003). The ethnography of communication. Oxford: Blackwell Publishing.

Unsworth, L. (2001). Teaching multiliteracies across the curriculum. Buckingham: Open University Press.

Vass, E. (2004). Understanding collaborative creativity. An observational study of young children's classroom-based joint creative writing. In K. L. D. Miell (Ed.), Collaborative creativity. London: Free Association Press.

Vass, Litlleton, Miell \& Jones. (2008). The discourse of collaborative creative writing: peer collaboration as a context for mutual inspiration. Thinking Skills and Creativity, 3(3), 192-202.

Vygotsky, L. S. (2004). Imagination and creativity in childhood. Journal of Russian and East European Psychology, 42(1), 7-97.

Wegerif, R. (2005). Reason and creativity in classroom dialogues. Language and Education, 19(3), 223-237.

Wertsch, J. V. (1991). Voices of the mind. Cambridge, MA: Harvard University Press.

Wertsch, J. V. (1998). Mind as action. New York: Oxford University Press. 